\title{
Future demands for high field MRI diagnostic
}

\author{
ANURAG GAUTAM ${ }^{\mathrm{a}, *}$ (1) , PRAGYA KOMAL $^{\mathrm{b}}$ and RAM SEVAK SINGH ${ }^{\mathrm{a}}$ \\ ${ }^{a}$ School of Science, O. P. Jindal University, Raigarh 496001, Chhattisgarh, India \\ ${ }^{b}$ Department of Biology, Birla Institute of Technology and Science, Pilani-Hyderabad Campus, \\ Jawaharnagar, Shamirpet Mandal, Hyderabad 500078, Telangana, India \\ E-mail: ganurag13@gmail.com
}

MS received 31 March 2019; revised 13 May 2019; accepted 15 May 2019

\begin{abstract}
In the near future there would be a need for a high field MRI contrast agent for the MRI diagnostic due to the several disadvantages of Gd-based complexes, such as short circulation time and decrease in efficiency at high magnetic field i.e., greater than $3 \mathrm{~T}$. The lanthanide-based nanoparticle can be an alternative to these complexes due to a high density of metal ions per unit of contrast agent. The high density of the metal ions will enable the MR signal shortening usually, at lower concentrations compared to chelates that typically are used at micro-molar concentrations. Additionally, the nanoparticles would retain their relaxivity efficiency at high magnetic field greater than $3 \mathrm{~T}$.
\end{abstract}

Keywords. MRI; nanoparticles; magnetic field; relaxivity.

\section{Introduction}

Nanoparticle-based (NP-based) imaging is currently advancing rapidly for biomedical application such as diagnostic imaging and cancer therapy. ${ }^{1-23}$ The major challenge to improve cancer therapy is the detection at early stages when the cancer is still confined to the site of its origin, which could facilitate a more favorable outcome. $^{2}$ Magnetic resonance imaging (MRI) is a powerful non-invasive diagnosis technique widely applied for clinical imaging. MRI has a submillimeter spatial resolution, allows whole (human) body scans, and provides details of many diseases. ${ }^{5-25}$ As MR image resolution increases with the strength of the magnetic field, high magnetic fields (e.g., $7 \mathrm{~T}$ or higher) are used for pre-clinical animal imaging while lower fields $(\leq 3 \mathrm{~T})$ are used for humans. The signal intensity in MRI depends on the proton density and on the $T_{1}$ and $T_{2}$ relaxation times of the water protons. As the water density is similar for various soft tissues, the differences in the relaxation times are used to provide contrast. However, the differences are often not sufficiently large to allow visible contrast between tumor and normal tissue. Therefore, the tumor contrast must be further improved, by the administration of a contrast agent (CA). The CAs are typically characterized as the enhancement in the $\mathrm{T}_{1}-$ the longitudinal (spin-

*For correspondence lattice) and $\mathrm{T}_{2}-$ transverse (spin-spin) relaxation rate of the nearby water proton. The enhancement in the relaxation rate is also known as relaxivity, represented as $r_{1}\left(=1 / T_{1}[\mathrm{CA}]\right)$ and $r_{2}\left(=1 / \mathrm{T}_{2}[\mathrm{CA}]\right) .^{10-13}$

The most commonly employed $\mathrm{T}_{1} \mathrm{CAs}$ are $\mathrm{Gd}^{3+}$ based chelates because $\mathrm{Gd}^{3+}$ strongly shortens $\mathrm{T}_{1}$ due to its seven unpaired electrons and long electronic relaxation time $\left(10^{-9} \mathrm{~s}\right) .^{13,20}$ These complexes show their suitable $r_{1}$-relaxivity at clinical magnetic field strengths (1.5-3.0 T). However, much higher magnetic fields $(>7 \mathrm{~T})$ are used for small animal (pre-clinical) imaging as the signal-to-noise, and thus resolution, is obtained at high field strength ${ }^{4,21}$ but smaller $\mathrm{Gd}^{3+}$ based chelates tumble very fast (faster than $10^{-10} \mathrm{~s}$ ) which drastically decreases their $r_{1}$-relaxivity at higher fields. ${ }^{16}$ Moreover, these chelates have short circulation time due to fast renal excretion limiting further their usefulness in small-animal studies. ${ }^{7,15}$ Usually, the short circulation time has been overcome by combining the $\mathrm{Gd}^{3+}$ ion with bigger proteins and polymer molecules, but the tumbling times of such complexes are still too fast $\left(10^{-10} \mathrm{~s}\right)$ for optimal performance at higher magnetic fields. ${ }^{71}$ In contrast, selected NPs with longer tumbling times can overcome the shortcomings of these $\mathrm{Gd}^{3+}$-based complexes. The NPs have a high density of metal ions per unit of CA enabling MR signal shortening at lower concentrations compared to chelate that usually are used at micro-molar concentrations. ${ }^{15,14}$ 
NP-based CAs can broadly be categorized into two major classes, namely iron-based and $\mathrm{Ln}^{3+}$-based NPs. ${ }^{14,18}$ Iron oxide NPs $(<3 \mathrm{~nm})$ have been demonstrated as a $\mathrm{T}_{1}$ CAs owing to the low magnetic moment, while the bigger iron oxide NPs are known as $\mathrm{T}_{2}$ CAs due their superparamagnetic (SP) nature. ${ }^{15,18}$ Nevertheless, smaller iron oxide NPs are known to be unstable in biological media and the size uniformity is still challenging for the bigger NPs. ${ }^{13,9}$ Additionally, SP iron oxide NPs could distort the magnetic field of the neighboring normal tissues and lead to magnetic susceptibility artifact which limits their clinical application. ${ }^{28}$ Therefore, to improve diagnostic capabilities of MRI, the iron oxide NPs labeled with $\mathrm{Gd}^{3+}$ complexes have been reported as $\mathrm{T}_{1}-\mathrm{T}_{2}$ dual-mode CAs. ${ }^{3,24}$ Consequently, to overcome the perturbation effect of SP iron oxide, ${ }^{28}$ manganese-loaded mesoporous silica NPs have been proposed for more accurate $T_{1}-T_{2}$ dual-mode imaging at clinically relevant fields. ${ }^{19}$ Therefore, for high-field $(>9.4 \mathrm{~T}$ ) MR imaging the paramagnetic lanthanide NPs could be a potential alternative because they show saturation magnetization at high field $(>30 \mathrm{~T})$ as demonstrated previously. $^{20}$

Recently, dysprosium $\left(\mathrm{Dy}^{3+}\right)$ ion has received much attention as a potential $T_{2}$ CA for high-magnetic-field MRI because of its high effective magnetic moment $\left(10.6 \mu_{\mathrm{B}}\right)$ and short electronic relaxation time $\left(\mathrm{T}_{1 \mathrm{e}} \sim 10^{-13} \mathrm{~s}\right) .^{20}$ The high effective magnetic moment of $\mathrm{Dy}^{3+}$ would lead to higher magnetic susceptibility per unit volume of the NPs (because one NP comprises a large number of $\mathrm{Dy}^{3+}$ ions) which causes greater local field perturbation and thus higher $r_{2}$-relaxivity. Moreover, the short $\mathrm{T}_{1 \mathrm{e}}$ of $\mathrm{Dy}^{3+}$ allows the Curie spin to return to thermal equilibrium before the molecule changes its position or tumbles and thus becomes an important contributor to relaxivity. ${ }^{20}$ Aforementioned, the long $\mathrm{T}_{1 \mathrm{e}}$ of $\mathrm{Gd}^{3+}$ makes it a suitable $\mathrm{T}_{1} \mathrm{CA}$ and $\mathrm{r}_{1}$-relaxivity particularly dominated by the $\mathrm{Gd}^{3+}$ at the surface. ${ }^{14,12}$ The use of combined $\mathrm{T}_{1} / \mathrm{T}_{2}$-weighted $\mathrm{MR}$ imaging that employs the same CAs could improve cancer detection (diagnostic MRI capability) accuracy and it could be achieved by $\mathrm{Dy}^{3+}$ and $\mathrm{Gd}^{3+}$ core/shell nanostructures as shown in the proposed scheme in Figure $1 .{ }^{12}$ However, in the current review we will discuss the capability of $\mathrm{NaDyF}_{4}$ nanoparticles as $\mathrm{T}_{2} \mathrm{CA}$ for high field MRI diagnostic.

\subsection{Experimental design}

The synthesis of hexagonal $\mathrm{NaREF}_{4}(\mathrm{RE}=\mathrm{Dy}, \mathrm{Gd}$, $\mathrm{Y})$ can be carried out with their RE (III) acetate hydrate or with RE(III) chloride hydrate. In a typical synthesis of $1 \mathrm{mmol}$ of $\mathrm{NaDyF}_{4}, 0.78 \mathrm{mmol}$ of dysprosium (III) chloride hydrates were added to $50 \mathrm{~mL}$ three-neck round bottom flask subsequently, added $1.5 \mathrm{~mL}$ oleic acid together with $7.5 \mathrm{~mL}$ of 1 -octadecene. ${ }^{1}$ Consequently, the mixtures were heated under vacuum to $140{ }^{\circ} \mathrm{C}$ with continuous stirring for $30 \mathrm{~min}$ that produces the dysprosium-oleates complex. The complex mixture was cool down to room temperature. Subsequently, added the $2.8 \mathrm{mmol}$ of $\mathrm{NaOH}$ and $4 \mathrm{mmol}$ of $\mathrm{NH}_{4} \mathrm{~F}$ dissolved in $7.5 \mathrm{~mL}$ of methanol that precipitated the complex. Later, the precipitates were mixed together at room temperature $\left(25^{\circ} \mathrm{C}\right)$ that gave the homogenous solution mixture. Then the temperature of the solution mixture was slowly raised to $65{ }^{\circ} \mathrm{C}$ to remove the methanol and other impurities such as chlorides from the solution mixture. After the removal of the impurities, the temperature of the solution mixture was raised to $\sim 300{ }^{\circ} \mathrm{C}$ at the rate $\sim 15$ to $20{ }^{\circ} \mathrm{C}$ per minutes for $1.5 \mathrm{~h}$ in an inert gas atmosphere. Subsequently, the mixture was cool down to room temperature and precipitated with an excess of ethanol and washed out by centrifugation. The obtained product was hexagonal oleate-stabilized $\mathrm{NaREF}_{4}$ nanoparticles. The sizes of these nanoparticles can be tuned with respect to reaction time. The nanoparticles synthesized up to this stage (assume stage I) would act as either $T_{1}$ or $T_{2}$ contrast agent, because the synthesized product would be $\mathrm{NaGdF}_{4}$ or $\mathrm{NaDyF}_{4}$ i.e., only the core nanoparticles.

In case of the materials, needed for both $T_{1}-T_{2}$ diagnostic simultaneously, at stage $\mathrm{I}$, the pre-synthesized calculated amount of sacrificial, cubic $\mathrm{NaGdF}_{4}$ nanoparticles would be injected and after the completion of the reaction the product would be oleate-stabilized $\mathrm{NaDyF}_{4} / \mathrm{NaGdF}_{4}$ nanoparticles. The synthesis of cubic nanoparticles has been reported. ${ }^{1}$

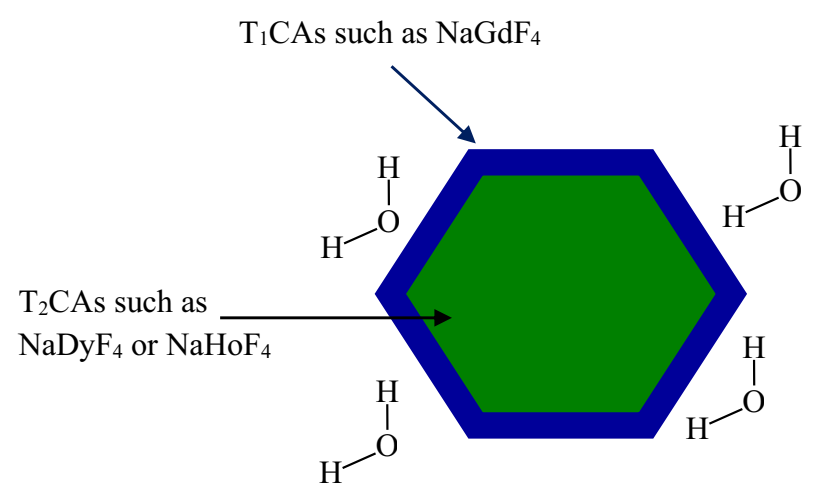

Figure 1. Schematic representation of the model for $\mathrm{T}_{1-}$ $\mathrm{T}_{2}$ MRI diagnostic simultaneously. 
However, as we mentioned earlier the plan in this review is to discuss more about $\mathrm{NaDyF}_{4}$ nanoparticles that are a potent $\mathrm{T}_{2}$ MRI contrast agent. The desired $\mathrm{NaDyF}_{4}$ nanoparticles of any size can be achieved adjusting reaction time. Their syntheses are very similar as proposed in the scheme in Figure 2. For instance, different sizes of nanoparticles $5.4 \mathrm{~nm}$,
$9.8 \mathrm{~nm}$, and $20.3 \mathrm{~nm}$ have been reported (Figure 3); ${ }^{10}$ their shapes were nearly spherical as shown in Figure 4. The surface modifications of these oleatestabilized $\mathrm{NaDyF}_{4}$ nanoparticles were performed with amphiphilic poly(maleic anhydride-alt-1-octadecene) (PMAO) and poly(ethylene glycol) methyl ether (PEG-OH) using chloroform as a solvent. After the

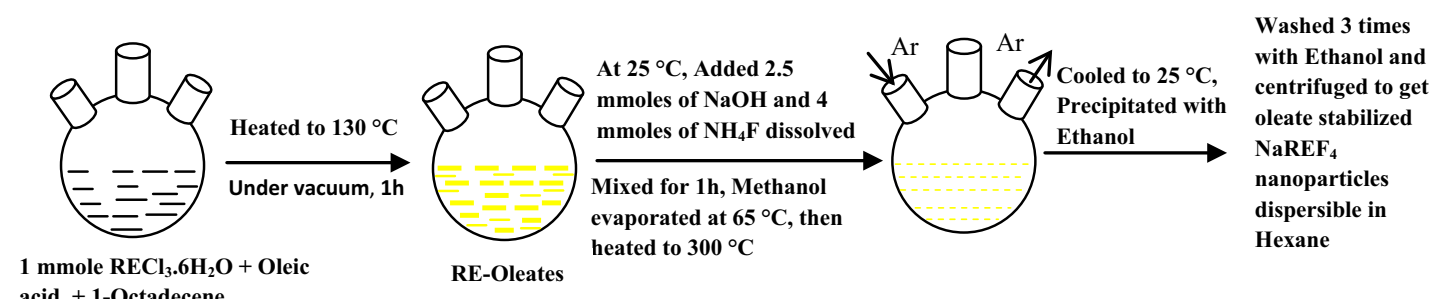

Figure 2. Schematic representation of the synthesis process of $\mathrm{NaREF}_{4}$ nanoparticles.
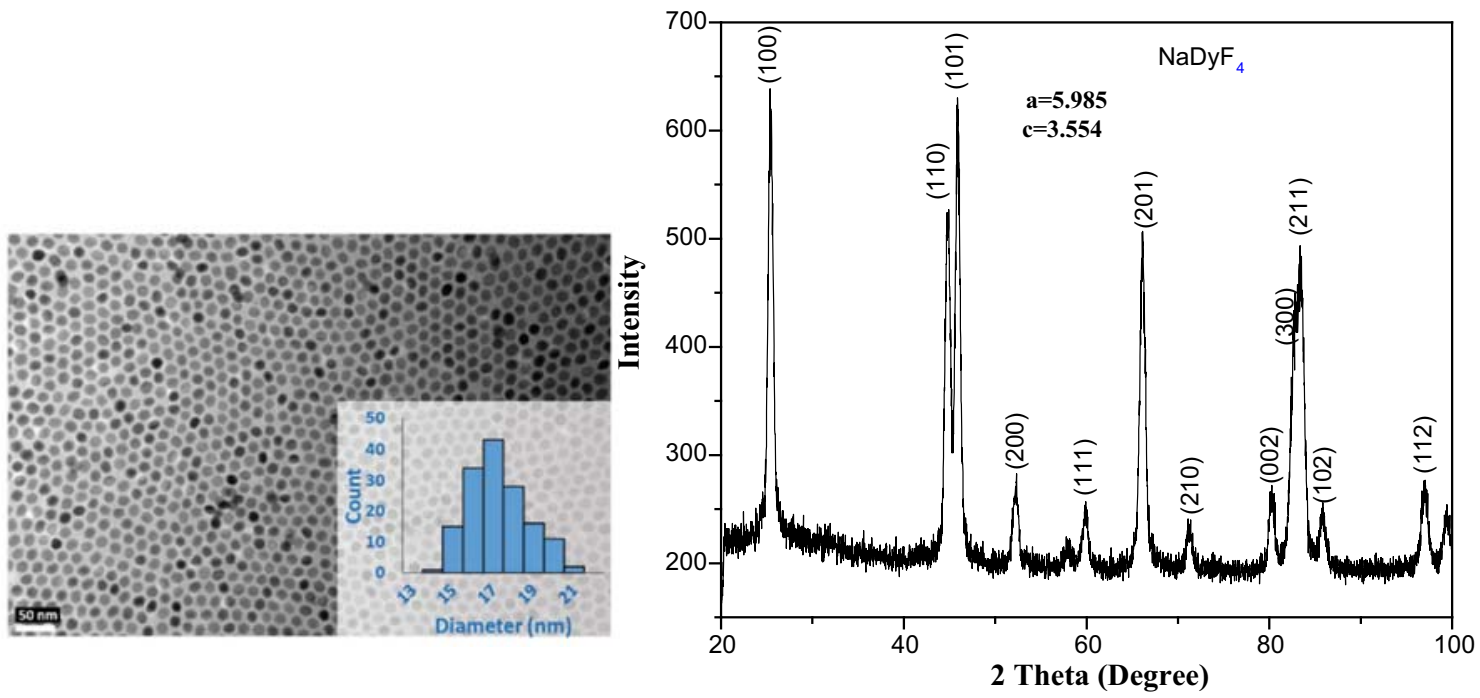

Figure 3. (a) The TEM image and (b) $\mathrm{XRD}$ of synthesized $\mathrm{NaDyF}_{4}$ nanoparticles. This figure is reprinted with permission from Ref. ${ }^{1}$ Copyright (2017) American Chemical Society.
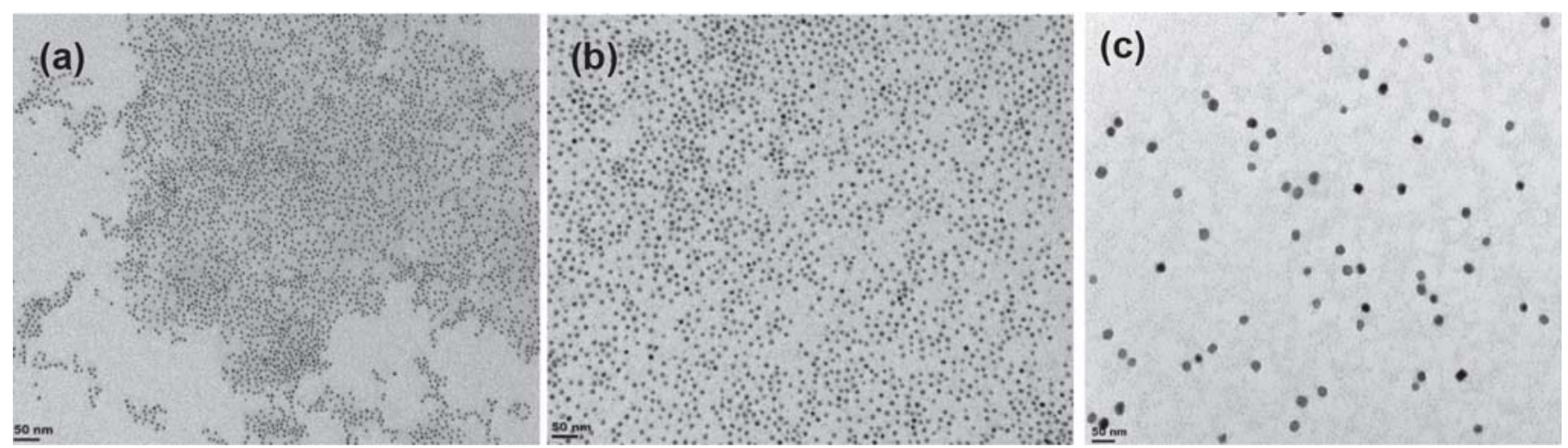

Figure 4. TEM image of $\mathrm{NaDyF}_{4}$ nanoparticles (a) $5.4 \mathrm{~nm}$, (b) $9.8 \mathrm{~nm}$ and (c) $20.3 \mathrm{~nm}$. This figure is reprinted with permission from Ref. ${ }^{10}$ Copyright (2011) American Chemical Society. 


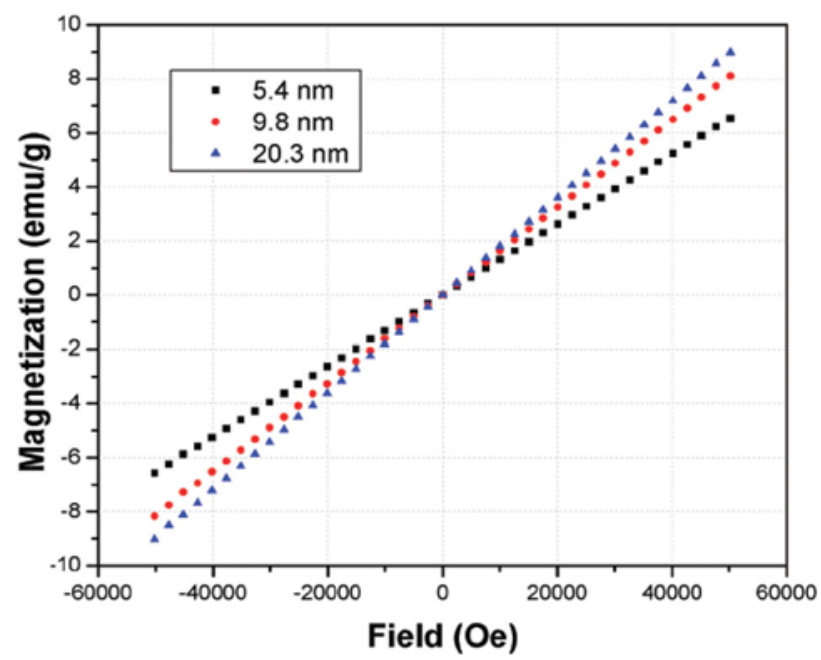

Figure 5. SQUID magnetometer data of mass magnetize $\mathrm{NaDyF}_{4}$ nanoparticles. This figure is reprinted with permission from Ref. ${ }^{10}$ Copyright (2011) American Chemical Society.

evaporation of the chloroform, the water dispersible PMAO-PEG modified nanoparticles were obtained. ${ }^{10}$

The SQUID magnetometer of $\mathrm{NaDyF}_{4}$ nanoparticles of sizes 5.4, 9.8 and $20.3 \mathrm{~nm}$ has been reported by Gautom et al. ${ }^{10}$ shown in Figure 5. It is clear from Figure 5 that magnetization of nanoparticles increases with the increase in the size of the particles. The reasons of increase in the magnetization of the bigger nanoparticles were due to the availability of a greater number of $\mathrm{Dy}^{3+}$ compared to their availability in the smaller nanoparticles. Usually, the overall magnetization of the nanoparticles remained independent of the shape for $\mathrm{NaDyF}_{4}$ nanoparticles as reported by Zhang et $a l .{ }^{27}$ For instance, as shown in Figure 6, the measured magnetization of rod-like $\mathrm{NaDyF}_{4}$ nanoparticles of dimension $(15 \mathrm{~nm} \times 20 \mathrm{~nm})$ was nearly $7 \mathrm{emu} / \mathrm{g}$, however as the dimension changes to $(19 \mathrm{~nm} \times 25 \mathrm{~nm})$ the magnetization changed to $8 \mathrm{emu} / \mathrm{g}$ at 7 Oersted. ${ }^{27}$ Furthermore, as the size of nanoparticles increases to $25 \mathrm{~nm} \times 35 \mathrm{~nm}$, the magnetization increases to $10.8 \mathrm{emu} / \mathrm{g}$ at the same magnetic field. ${ }^{27}$ The surfaces of these oleate-stabilized (hydrophobic in nature) nanoparticles were further modified with PMAO-PEG in order to disperse in water. $^{10,27}$

\subsection{Relaxivity measurement of the PMAP-PEG coated $\mathrm{NaDyF}_{4}$ nanoparticles}

Relaxivity of a CA can be defined as a change in the relaxation rate after addition of a $\mathrm{CA}$, normalized to
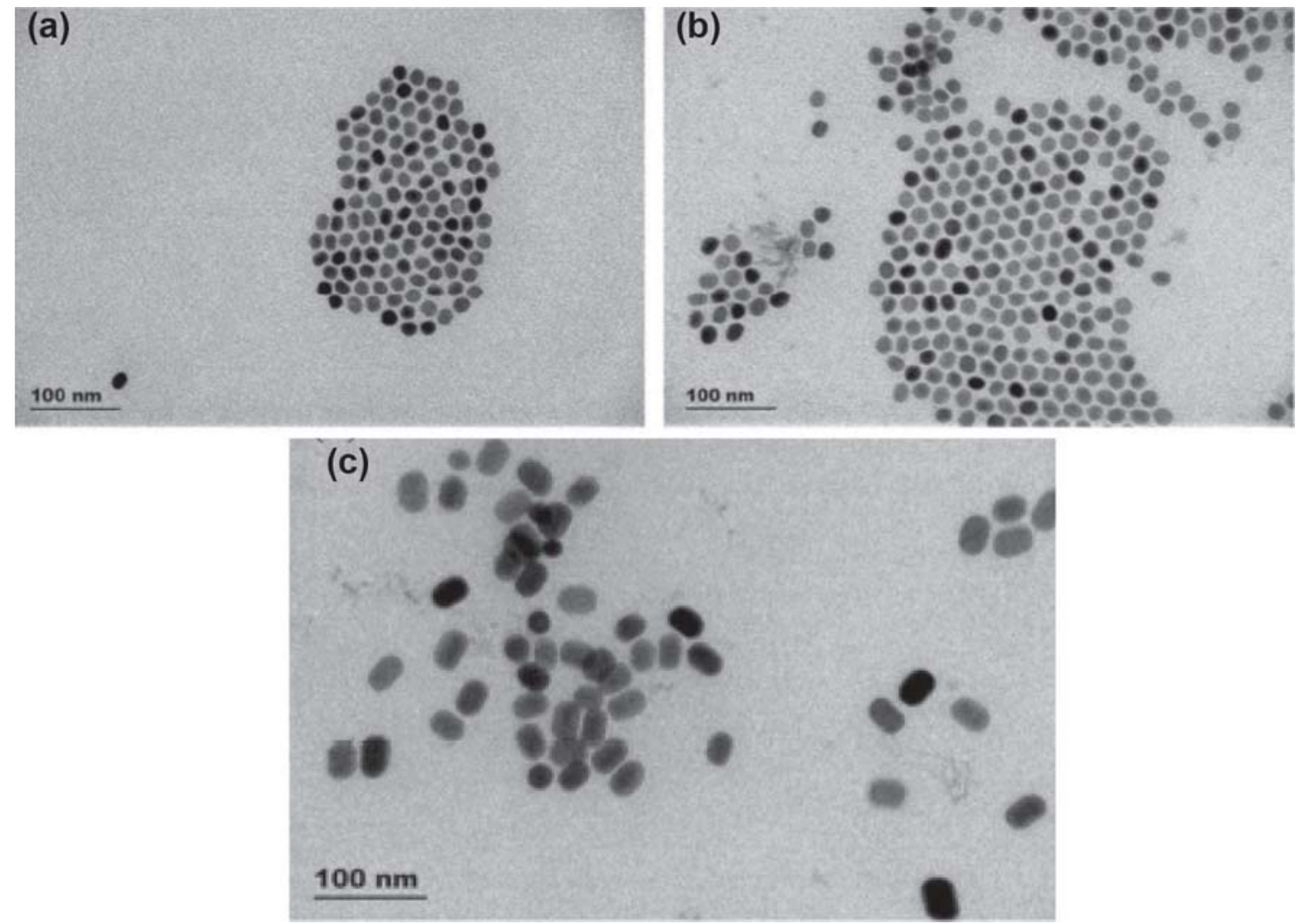

Figure 6. TEM image of $\mathrm{NaDyF}_{4}$ nanoparticles of sizes (a) $15 \mathrm{~nm} \times 20 \mathrm{~nm}$, (b) $19 \mathrm{~nm} \times 25 \mathrm{~nm}$ and (c) $25 \mathrm{~nm} \times 35 \mathrm{~nm}$. This figure is reprinted with permission from Ref. ${ }^{27}$ Copyright (2016) American Chemical Society. 
Table 1. $\mathrm{r}_{2}$-relaxivities of $\mathrm{NaDyF}_{4}$ nanoparticles and $9.4 \mathrm{~T}$.

\begin{tabular}{|c|c|c|c|c|c|c|}
\hline Contrast agents & Size $(\mathrm{nm})$ & Shape & $\mathrm{r}_{2}\left[\mathrm{Dy}^{3+}\right]\left(\mathrm{mM}^{-1} \mathrm{~s}^{-1}\right)$ & per NPs $\left(\mathrm{mM}^{-1} \mathrm{~s}^{-1}\right)$ & Surface coating & References \\
\hline $\mathrm{NaDyF}_{4}$ & 5.4 & Spherical & 32 & $50 \times 10^{4}$ & PMAO-PEG & 10 \\
\hline $\mathrm{NaDyF}_{4}$ & 9.8 & Spherical & 51 & $350 \times 10^{4}$ & PMAO-PEG & 10 \\
\hline $\mathrm{NaDyF}_{4}$ & 20.3 & Spherical & 101 & $570 \times 10^{4}$ & PMAO-PEG & 10 \\
\hline $\mathrm{NaDyF}_{4}$ & $15 \times 20$ & Elongated & 65 & $313 \times 10^{4}$ & PMAO-PEG & 27 \\
\hline $\mathrm{NaDyF}_{4}$ & $19 \times 25$ & Elongated & 91 & $1117 \times 10^{4}$ & PMAO-PEG & 27 \\
\hline $\mathrm{NaDyF}_{4}$ & $25 \times 35$ & Elongated & 204 & $4767 \times 10^{4}$ & PMAO-PEG & 27 \\
\hline
\end{tabular}
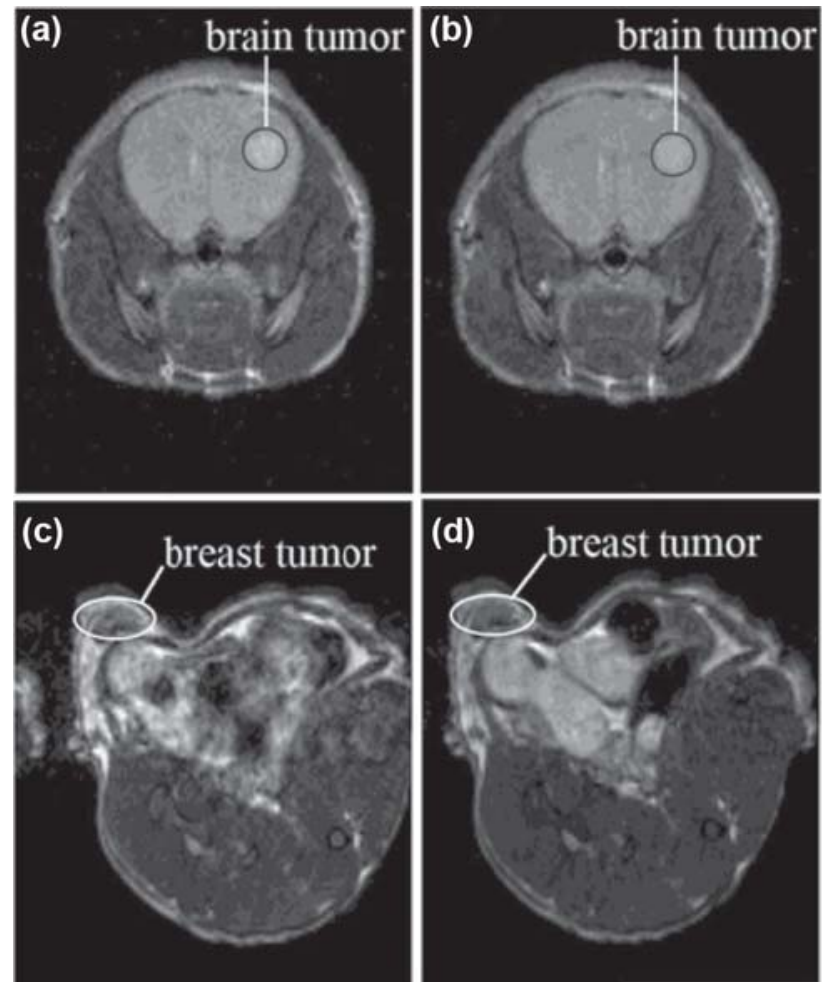

Figure 7. In vivo $\mathrm{T}_{2}$-weighted $\mathrm{MR}$ images of tumor bearing mice: brain tumor and breast tumor before (left) and 12 min post injection (right) of the $\mathrm{NaDyF}_{4}$ nanoparticles. This figure is reprinted with permission from Ref. ${ }^{27}$ Copyright (2016) American Chemical Society.

the concentration of the $\mathrm{CA}$. The equation is given below, ${ }^{6,12}$

$\mathrm{r}_{\mathrm{i}}=\Delta\left(1 / \mathrm{T}_{\mathrm{i}}\right) /[\mathrm{M}]$,

where $\mathrm{i}=1$ or 2 , and $\mathrm{M}$ is the concentration of $\mathrm{CA}$.

As we mentioned the $\mathrm{NaDyF}_{4}$ is $\mathrm{T}_{2}$ contrast agent, therefore for the $\mathrm{Dy}^{3+}$-based nanoparticles $(\mathrm{i}=2)$ then

$\mathrm{r}_{2}=\Delta\left(1 / \mathrm{T}_{2}\right) /[\mathrm{M}]$,

The relaxivity is usually governed by the in-sphere and outer-sphere mechanism for lanthanide-based complexes. ${ }^{12}$ However, due to the hydrophobic barrier on the surface of nanoparticles, the water molecules get prohibited to reach the surface of the metal nanoparticles. Therefore, the only out-sphere contribution is expected that will lead to $r_{2}$-relaxivity (Table 1).

Zhang et al. ${ }^{27}$ achieved the highest $\mathrm{r}_{2}$-relaxivity $204 \mathrm{mM}^{-1} \mathrm{~s}^{-1}$ per $\mathrm{Dy}^{3+}$ with the $25 \mathrm{~nm} \times 35 \mathrm{~nm}$, elongated $\mathrm{NaDyF}_{4}$ nanoparticles. Therefore, it was more appropriate for MRI at high field $(9.4 \mathrm{~T})$ and used for MR imaging of the brain tumor and breast tumor of mice. These nanoparticles were injected into mice via the tail vein. The amount of nanoparticles injected was $0.25 \mathrm{~mL}$ of NaDyF4 $(25 \mathrm{~nm} \times 35 \mathrm{~nm})$ in water weighing $2 \mathrm{mg} / \mathrm{mL}$ of $\mathrm{NaDyF}_{4}$. The MR images are shown in Figure 7. Figure $7 \mathrm{a}$ shows the brain tumor (high-grade glioma) bearing the image before injection of nanoparticles. Figure $7 \mathrm{~b}$ shows the brain tumor (high-grade glioma) bearing image $12 \mathrm{~min}$ post injection of the $\mathrm{NaDyF}_{4}$ nanoparticles. The contrasts between the tumor and brain tissue are evidently seen in Figure $7 \mathrm{a}$ and $7 \mathrm{~b}$. The increased $\mathrm{T}_{2}$ contrast can be seen in Figure $7 b$, due to the accumulation of $\mathrm{NaDyF}_{4}$ nanoparticles at the tumor site. The similar effects were also seen in breast tumor Figure $7 \mathrm{c}$ and $7 \mathrm{~d}$ before and after injection respectively. The maximum $\mathrm{T}_{2}$ reduction was $13.5 \%$ just after the injection of the $\mathrm{NaDyF}_{4}$ nanoparticles. The result suggested that $\mathrm{NaDyF}_{4}$ nanoparticles were effective in the detection of both brain and breast tumors. ${ }^{27}$

\section{Conclusions}

In this article, we have discussed why there is need of a relevant CA for a high magnetic field application. Additionally, we discussed the advantages of $\mathrm{NaREF}_{4}$ nanoparticles over the RE-based complexes $(\mathrm{RE}=\mathrm{Gd}$, Dy) as an MRI CA. Moreover, we have compared the SQUID magnetometer data of $\mathrm{NaDyF}_{4}$ nanoparticles of different size and shapes. The result suggested that magnetization was independent of the shape for $\mathrm{NaDyF}_{4}$ nanoparticles. However, the magnetization of nanoparticles increases with the increasing particles size. The reason of increase in the 
magnetization of the bigger nanoparticles was due to the availability of a greater number of $\mathrm{Dy}^{3+}$ compared to their availability in the smaller nanoparticles. Finally, the biggest size i.e., $25 \mathrm{~nm} \times 35 \mathrm{~nm}$ elongated $\mathrm{NaDyF}_{4}$ nanoparticles were used for the MRI of brain and breast tumors at $9.4 \mathrm{~T}$ had shown good contrast between normal brain tissue and the tumor region. The result suggested the $\mathrm{NaDyF}_{4}$ nanoparticles have the potential for high field MRI applications as $\mathrm{T}_{2} \mathrm{CA}$.

\section{References}

1. Alvares R D A, Gautam A, Prosser R S, van Veggel F C J M and Macdonald P M 2017 Shell versus core $\mathrm{Dy}^{3+}$ contributions to NMR water relaxation in sodium lanthanide fluoride core-shell nanoparticles. An investigation using O-17 and H-1 NMR J. Phys. Chem. C 12117552

2. Arya S K and Bhansali S 2011 Lung cancer and its early detection using biomarker-based biosensors. Chem. Rev. 1116783

3. Bae K H, Kim Y B, Lee Y, Hwang J, Park H and Park T G 2010 Bioinspired synthesis and characterization of gadolinium-labeled magnetite nanoparticles for dual contrast $T_{1^{-}}$and $T_{2}$-weighted magnetic resonance imaging Bioconjugate Chem. 21505

4. Bokacheva L, Ackerstaff E, LeKaye H C, Zakian K and Koutcher J A 2014 High-field small animal magnetic resonance oncology studies Phys. Med. Biol. 59 R65

5. Cao C, Wang X, Cai Y, Sun L, Tian L, Wu H, He X, Lei H, Liu W, Chen G, Zhu R and Pan Y 2014 Targeted in vivo imaging of microscopic tumors with ferritinbased nanoprobes across biological barriers $A d v$. Mater. 262566

6. Caravan P, Ellison J J, McMurry T J and Lauffer R B 1999 Gadolinium(III) chelates as MRI contrast agents: structure, dynamics, and applications Chem. Rev. 99 2293

7. Caravan P, Farrar C T, Frullano L and Uppal R 2009 Influence of molecular parameters and increasing magnetic field strength on relaxivity of gadoliniumand manganese-based T1 contrast agents Contrast Media Mol. Imaging 489

8. Chen S, Wang L, Duce S L, Brown S, Lee S, Melzer A, Cuschieri S A and André P 2010 Engineered biocompatible nanoparticles for in vivo imaging applications J. Am. Chem. Soc. 13215022

9. Coey J M D 1971 Noncollinear spin arrangement in ultrafine ferrimagnetic crystallites Phys. Rev. Lett. 27 1140

10. Das G K, Johnson N J J, Cramen J, Blasiak B, Latta P, Tomanek, B and van Veggel F C J M 2012

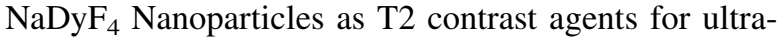
high field magnetic resonance imaging J. Phys. Chem. Lett. 3524

11. Debroye E and Parac Vogt T N 2014 Towards polymetallic lanthanide complexes as dual contrast agents for magnetic resonance and optical imaging Chem. Soc. Rev. $\mathbf{4 3} 8178$
12. Gautam A and Komal P 2018 Probable ideal size of $\mathrm{Ln}^{3+}$-based upconversion nanoparticles for single and multimodal imaging Coord. Chem. Rev. 376393

13. Gautam A and van Veggel F C J M 2013 Synthesis of nanoparticles, their biocompatibility, and toxicity behavior for biomedical applications J. Mater. Chem. B 15186

14. Johnson N J J, Oakden W, Stanisz G J, Scott Prosser R and van Veggel F C J M 2011 Size-tunable, ultrasmall $\mathrm{NaGdF}_{4}$ nanoparticles: Insights into their $\mathrm{T}_{1} \mathrm{MRI}$ contrast enhancement Chem. Mater. 233714

15. Kim B H, Lee N, Kim H, An K, Park Y I, Choi Y, Shin K, Lee Y, Kwon S G, Na H B, Park J G, Ahn T Y, Kim Y W, Moon W K, Choi S H and Hyeon T 2011 Largescale synthesis of uniform and extremely small-sized iron oxide nanoparticles for high-resolution $T_{1}$ magnetic resonance imaging Contrast Agents J. Am. Chem. Soc. 13312624

16. Lee G Y, Qian W P, Wang L, Wang Y A, Staley C A, Satpathy M, Nie S, Mao H and Yang L 2013 Theranostic nanoparticles with controlled release of gemcitabine for targeted therapy and MRI of pancreatic cancer ACS Nano 72078

17. Mahmoudi M, Hosseinkhani H, Hosseinkhani $M$, Boutry S, Simchi A, Journeay W S, Subramani K and Laurent S 2011 Magnetic resonance imaging tracking of stem cells in vivo using iron oxide nanoparticles as a tool for the advancement of clinical regenerative medicine Chem. Rev. 111253

18. Na H B, Song I C and Hyeon T 2009 Inorganic nanoparticles for MRI contrast agents Adv. Mater. 21 2133

19. Niu D, Luo X, Li Y, Liu X, Wang X and Shi J 2013 Manganese-loaded dual-mesoporous silica spheres for efficient T1- and T2-weighted dual mode magnetic resonance imaging ACS Appl. Mater. Interfaces 59942

20. Norek M and Peters J A 2011 MRI Contrast agents based on dysprosium or holmium Progr. Nucl. Magn. Reson. Spectrosc. 5964

21. Ooi $Y$, Inui Yamamoto $C$, Suzuki $T$, Nakadate $H$, Nagase Y, Seiyama A, Yoshioka Y and Seki J 2014 In vivo magnetic resonance imaging at 11.7 tesla visualized the effects of neonatal transection of infraorbital nerve upon primary and secondary trigeminal pathways in rats Brain Res. 157984

22. Seo W S, Lee J H, Sun X, Suzuki Y, Mann D, Liu Z, Terashima M, Yang P C, McConnell M V, Nishimura D G and Dai H 2006 FeCo/graphitic-shell nanocrystals as advanced magnetic-resonance-imaging and near-infrared agents Nat. Mater. 5971

23. Wu M, Meng Q, Chen Y, Xu P, Zhang S, Li Y, Zhang L, Wang M, Yao H and Shi J 2014 Ultrasmall confined iron oxide nanoparticle MSNs as a $\mathrm{pH}$-responsive theranostic platform Adv. Funct. Mater. 244273

24. Yang H, Zhuang Y, Sun Y, Dai A, Shi X, Wu D, Li F, $\mathrm{Hu} \mathrm{H}$ and Yang S 2011 Targeted dual-contrast T1- and T2-weighted magnetic resonance imaging of tumors using multifunctional gadolinium-labeled superparamagnetic iron oxide nanoparticles Biomaterials 324584

25. Yeh C S, Su C H, Ho W Y, Huang C C, Chang J C, Chien Y H, Hung S T, Liau M C and Ho H Y 2013 Tumor targeting and MR imaging with lipophilic 
cyanine-mediated near-infrared responsive porous $\mathrm{Gd}$ silicate nanoparticles Biomaterials 345677

26. Yoo D, Lee J H, Shin T H and Cheon J 2011 Theranostic magnetic nanoparticles Acc. Chem. Res. 44863

27. Zhang $X$, Blasiak B, Marenco A J, Trudel S, Tomanek B and van Veggel F C J M 2016 Design and regulation of $\mathrm{NaHoF}_{4}$ and $\mathrm{NaDyF}_{4}$ nanoparticles for high-field magnetic resonance imaging Chem. Mater. 283060

28. Zhou Z, Huang D, Bao J, Chen Q, Liu G, Chen Z, Chen $\mathrm{X}$ and Gao J A 2012 Synergistically enhanced $T_{1}-$ $T_{2}$ dual-modal contrast agent Adv. Mater. 246223 